Editorial

\title{
Environmental Biogeochemistry of Elements and Emerging Contaminants
}

\author{
Xiao-San Luo $\mathbb{i}^{1}$ and Peng Wang ${ }^{2}$ \\ ${ }^{1}$ International Center for Ecology, Meteorology, and Environment, School of Applied Meteorology, \\ Nanjing University of Information Science \& Technology, Nanjing 210044, China \\ ${ }^{2}$ College of Resources and Environmental Sciences, Nanjing Agricultural University, Nanjing 210095, China
}

Correspondence should be addressed to Xiao-San Luo; xsluo@nuist.edu.cn

Received 16 May 2018; Accepted 17 May 2018; Published 5 July 2018

Copyright (c) 2018 Xiao-San Luo and Peng Wang. This is an open access article distributed under the Creative Commons Attribution License, which permits unrestricted use, distribution, and reproduction in any medium, provided the original work is properly cited.

As the hot issues of environment and geochemistry sciences, environmental biogeochemistry investigating both elements and pollutants in soil, water, air, and organism links their behavior and effects in pedosphere, hydrosphere, atmosphere, and biosphere systematically. Typically, biogeochemical cycles of some biogenic elements, such as carbon and nitrogen, are closely related to the global climate change through greenhouse gases, while some trace elements, usually known as toxic heavy metals in the environment, pose significant risks to both ecosystem and humans. Besides the traditional chemical pollutants, recently, the emerging contaminants, such as persistent organic pollutants (POPs), nanoparticles, microplastics, antibiotics, and antibiotic resistance genes (ARG), have been attracting extensive concerns, due to their potential environmental risks. Therefore, faced with these challenges, investigations of the environmental biogeochemistry of elements and emerging contaminants are of great significance for the environmental protection and human health.

This special issue aims to provide the environmental research community with a forum to share various innovative ideas and to present up-to-date advancements in these fields. The selected seven research papers might not fully cover the topics mentioned above, since six of them are mainly related to heavy metals, and the other paper introduces the risks threatened by acid rain with atmospheric pollutants. However, they represent how current research studies still focus on the long-term practical issue of environmental biogeochemistry of this traditional nondegradable pollutant, through illustrating the pollution sources, distribution, behavior, fate, ecological effects and risks, and management, control, and remediation of heavy metals in soil and water environments.

Knowing pollution sources and risk implications is the primary step in environmental biogeochemistry of pollutants. Mining activities can cause significant soil and water pollution through solid wastes and metal-rich effluents. The mobility, chemical speciation, and ecological risks of heavy metals $(\mathrm{Cu}, \mathrm{Pb}$, and $\mathrm{Zn}$ ) and the acid mine drainage (AMD) production in tailings of a copper mine in northern China were investigated by Chen et al. using column leaching studies. Besides the high metal concentrations in both tailings and leachates, the sequential extraction results and risk assessment code (RAC) evaluation based on the percentage of mobile fractions also revealed that heavy metals in tailings pose medium to high migration risks, which were influenced by specific hydrogeological and climate conditions. Rainfall is an important sink of scavenging atmospheric pollutants $\left(\mathrm{SO}_{2}, \mathrm{NO}_{x}\right.$, and particulate matters), and it is also a significant pollutant source to soil and water ecosystems, inducing negative environmental effects such as soil acidification and eutrophication. Chemical compositions of precipitation in the typical urban site of hinterland were reported by Zhang et al. through analyzing the watersoluble ions for two-year daily samples in the Three Gorges Reservoir, China. Results showed still serious air pollution $\left(\mathrm{SO}_{4}{ }^{2-}, \mathrm{NO}_{3}{ }^{-}\right.$, and $\left.\mathrm{NH}_{4}{ }^{+}\right)$by local anthropogenic activities such as coal burning and traffic-related sources together with agricultural activities, although the air quality has been improved in the recent decade. Excessive sulfur emission 
was the main precipitation acidity (average $\mathrm{pH}$ 5.0) factor, but the contribution of nitric acid was strengthening.

Key environmental biogeochemical processes include the distribution, transport, and fate of contaminants in the soil and aquatic systems, which are the main pollutant sinks and pose directly negative biological effects. The distribution and sources of heavy metals in both the waters and sediments of the Voghji River Basin (Armenia) were extensively investigated by Gabrielyan et al. to assess the environmental pollution ( $\mathrm{Mn}, \mathrm{Co}, \mathrm{Cu}, \mathrm{Zn}, \mathrm{Mo}, \mathrm{Cd}$, and $\mathrm{Pb}$ ) dramatically aggravated by drainage water and wastewater of mining regions, which disturbed the local geochemical balance. The coastal zone is also frequently disturbed by human activities such as land reclamation engineering which influences aquatic environment significantly. The spatial distributions of heavy metals in surface sediments after the land reclamation in Bohai Bay, China, were studied by Zhu et al. through grain size and speciation analysis and ecological risk assessments, demonstrating the contamination of $\mathrm{Cd}$ and $\mathrm{Cr}$ and the significant role of hydrodynamic condition change on pollutant distribution. With regard to the biological effects of heavy metals, the root responses and the corresponding intracellular mechanisms (elongation, antioxidative enzyme activities, and lipid peroxidation) of duckweed to Cd stress were investigated by Xue et al. based on Cd speciation accumulated in roots, which could be a predictor of Cd toxicity to aquatic plants.

Finally, control and remediation of soil and water pollution is the problem-solving step. As typical ways of pollution control, source elimination, environmental remediation, and land safe use are feasible choices. For pollutant removal, Feloaded corn straw biochar was successfully synthesized by Fan et al. and used as adsorbent for enhanced arsenate removal from aqueous solution, suggesting that it can be an efficient green method for the remediation of As-contaminated water or soil. The As speciation analysis indicated three mechanisms were involved in As (V) removal: sorption, strong innersphere surface complexes, and partial occlusion into the crystalline Fe oxides or carbonized phase. For safe use of heavy metal-contaminated agricultural soil, intercropping of gramineous pasture ryegrass and leguminous pasture alfalfa was proposed by Cui et al. to increase the plant resistance to heavy metals, which reduces plant oxidative damage and increases antioxidant activity. As an alternative to phytostabilization, it provides a strategy to raise biomass and reduce the $\mathrm{Pb} \mathrm{ac}-$ cumulation by forage plants in contaminated environments.

Compiling these papers, we hope to enrich readers the most recent progresses on different aspects of environmental biogeochemistry. Of course, it is worth pointing out that the investigated objects should not be limited by technology; besides heavy metals, the environmental biogeochemistry of biogenic element cycles and emerging contaminants and their interactions among various environmental systems are also significant and are developing rapidly.

\section{Acknowledgments}

The Guest Editors would like to thank all the authors for their contributions to this special issue and appreciate all the reviewers and related editorial board members for critical assessments and valuable comments to improve the quality of these papers.

Xiao-San Luo

Peng Wang 

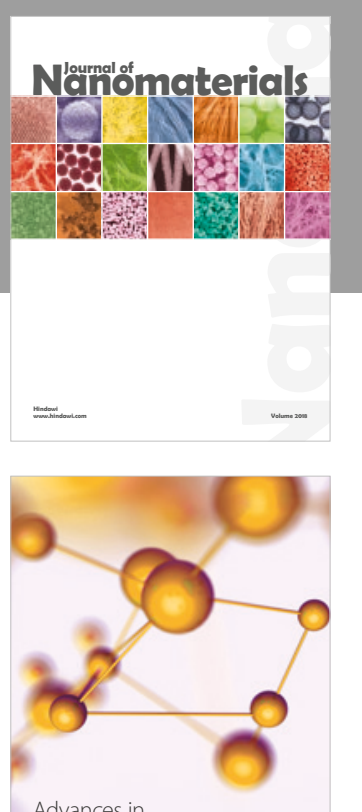

Physical Chemistry
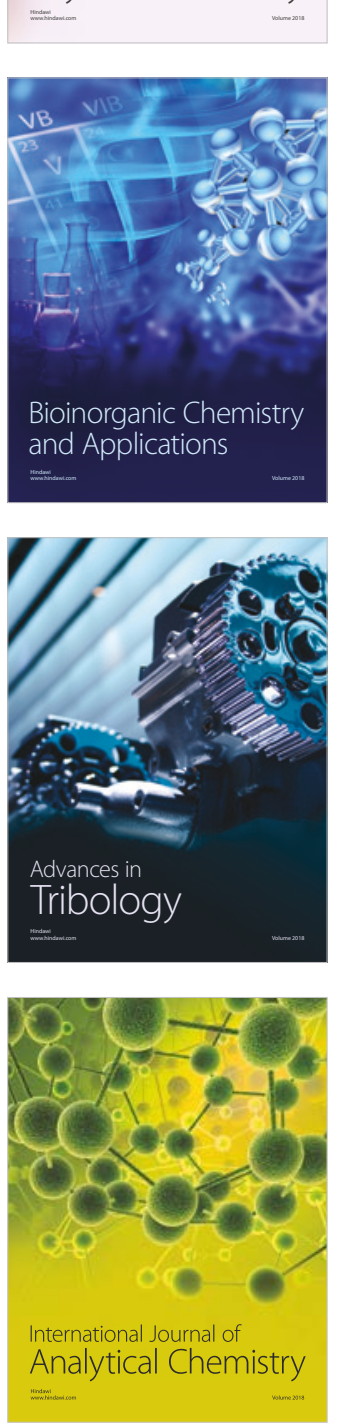

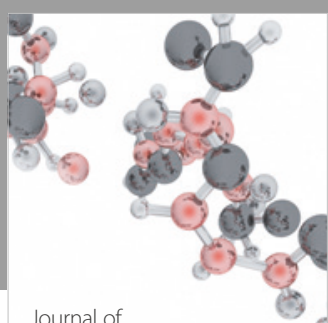

Analytical Methods

in Chemistry

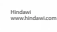

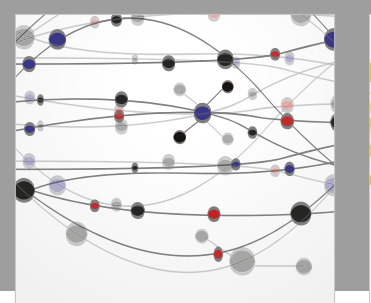

The Scientific World Journal

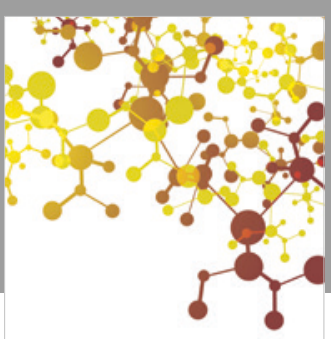

Journal of

Applied Chemistry
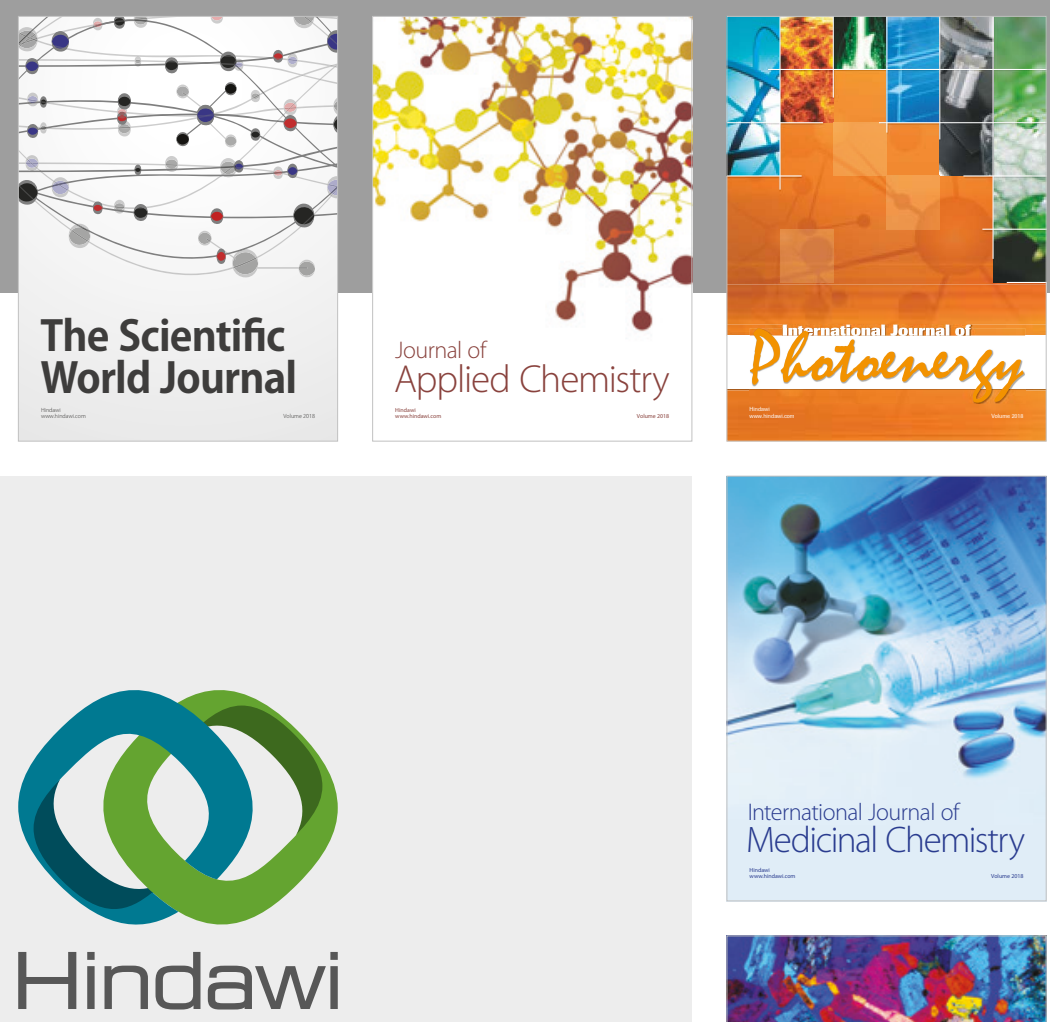

Submit your manuscripts at

www.hindawi.com
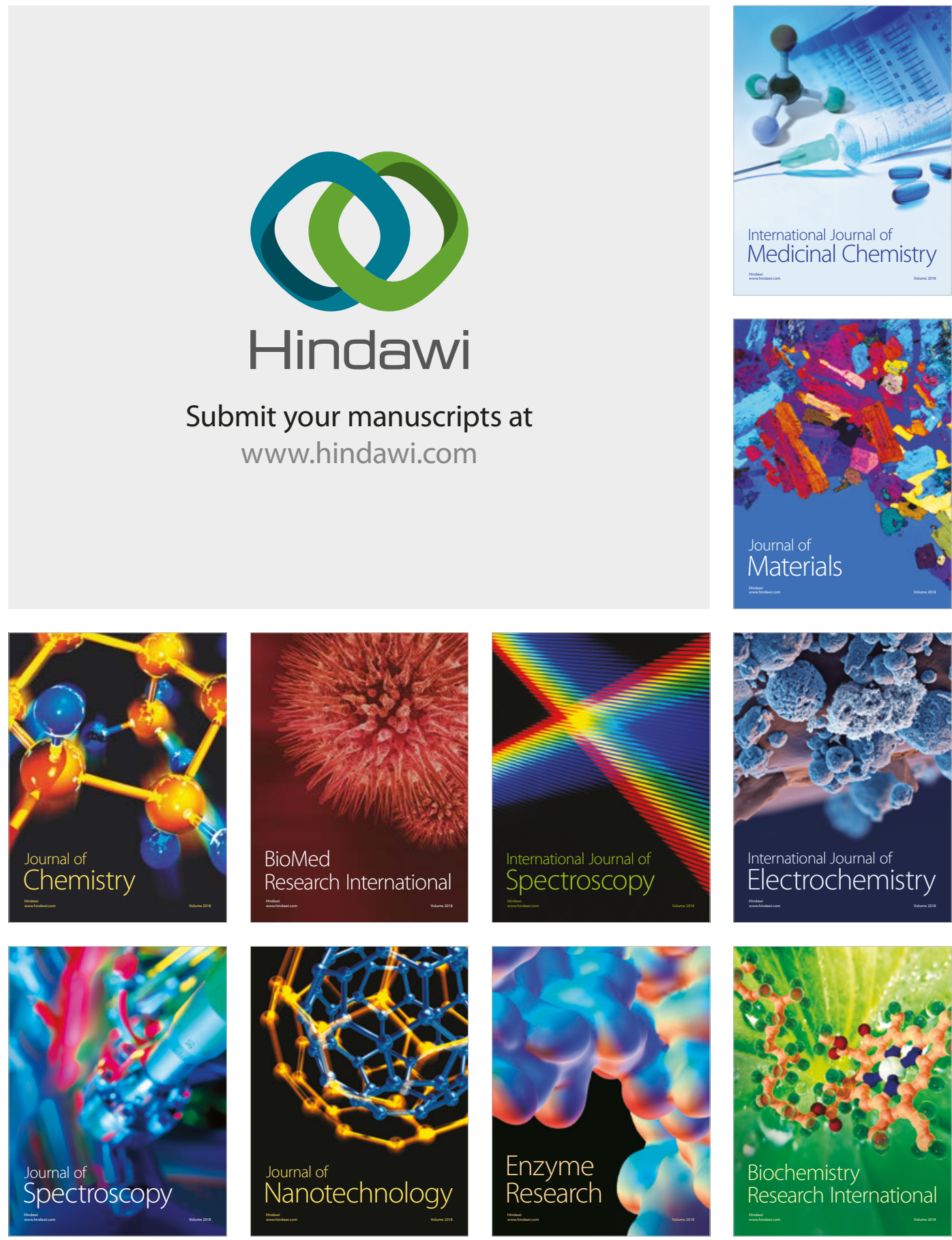
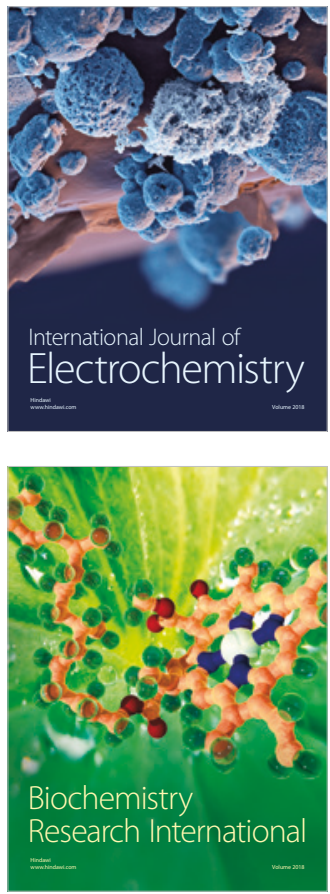